\title{
Involving and training public school teachers in using robotics for education
}

\author{
Fanny Riedo, Mariza Freire, Michael Bonani and Francesco Mondada
}

\begin{abstract}
The introduction of technology in the public school teaching process could help increasing the weak motivation we can observe toward engineering studies. To achieve this goal, one main obstacle is motivating public school teachers to use technological tools in their teaching activity. In this paper we present how to use a large public robotic festival to introduce such educational tools to teachers. A survey made among the teachers helps in understanding their expectations in this particular context and the potential impact of this action, giving hints on how to run this type of activity.
\end{abstract}

\section{INTRODUCTION}

Technology is massively present in our daily life, for instance in computers, phones, audio and video equipment, household appliances, and entertainment devices.

Understanding their impact, their potential and their risks requires an education where technology is analyzed and understood. Such education to technology should be spread among the whole population and could enable a better use of these promising tools. This ambitious educational goal should be part of the objectives of public schools. In Europe, despite a trend in including more and more technological tools into the learning process, teachers are still insufficiently trained and are reluctant to introduce them in their teaching activity [1]. Their poor training and motivation impacts also clearly on the understanding of their students, who are massive passive users of techonologies.

In parallel, robots seems to have a high potential as educational tools; they are at the same time fascinating and multidisciplinary, offering many possible educational contexts. Several examples show how to use robots to better support teaching activities. In Italy, teachers and university researchers have created a network to support the use of several robotic platforms by the teachers in schools [2]. Another example, centered more on gender issues in technology education, is the Roberta Initiative [3], based on the LEGO Mindstorms and providing to the teacher a broad set of teaching material. Rusk and Resnick also give interesting advice based on their experience and observations [4], which allow to broaden the participation to robotics workshops, courses and exhibitions.

This paper presents and analyzes one innovative way to motivate and train teachers in the use of educational robotic

\footnotetext{
This research was supported by the Swiss National Science Foundation through the National Centre of Competence in Research Robotics

F. Mondada, M. Freire and F. Riedo are with the Laboratory of Robotic Systems, Ecole Polytechnique Fédérale de Lausanne, Switzerland firstname.lastname@epfl.ch

Michael Bonani is with the Mobsya Association, Switzerland michael.bonani@mobsya.org
}

tools. The results give some hints on how to exploit robotics events, such as science festivals, to achieve this goal.

\section{EPFL ROBOTIC FESTIVAL AND TEACHERS}

Since 2008 we organize a robotic festival at the Ecole Polytechnique Fédérale de Lausanne (EPFL) [5]. This festival attracted 13'000 visitors in its 2011 edition. The festival's core activity consists in workshops where registered participants can have a specific supervised activity related to robotics. Workshops can be centered on robot programming, soldering of electronics components, problem solving with robotic kits, handiworks based on robots, construction of simple robotic systems, understanding of electronics principles etc. Most of these workshops use educational tools also used in schools: the Beebot robot [6], the LEGO Mindstorms [7] and WeDo kits, the BoeBot system [8] and others system which are not robots but are related to engineering and sciences. After having seen for several years some very motivated teachers participating as volunteering staff to these workshops, we understood that this activity could be an interesting opportunity to motivate also other teachers. The workshops could be indeed a nice opportunity for public schools teachers to learn about the use of technological tools with children.

\section{A. How to attract teachers}

A first attempt to simply advertise this activity to teachers within teacher training universities and schools has shown extremely poor impact. We first started advertising the event without considering the specific requirements of teachers. This has shown to be insufficient to motivate even a small minority of them. Teachers feedbacks showed that they need to see a direct use and advantage of the suggested technology for their classes. Moreover the tools should be ready-to-use and not require, in addition to the effort of understanding it, an effort in integrating them into the educational curriculum.

We started to propose the following package that proved to attract teachers :

- Each workshop has written pedagogical material, available in advance for consultation, and usable by the teachers afterwards in their class.

- Each teacher gets a training on the topic of the workshop before the workshop.

- Each teacher can choose the sessions where he or she would like to participate, with a fine granularity (down to one session).

- At the end of the workshop the teacher gets for free the equipment used in the workshop if the material value is 
less than $100 \mathrm{CHF}$. If the value is higher, a structure is created to allow the teachers to borrow the equipment for free.

Based on these conditions, about 30 teachers attended the festival 2011 as staff for the workshops and observer.

\section{B. Evaluation by a survey}

We contacted the teachers who attended the festival and asked them to fill a survey form to evaluate the experience. A translation of the questions asked in this form are given in table I. The questions are grouped in four sections: profile of the teacher, evaluation of the event, impact on the activities of the teachers, future of the event. Sixteen teachers filled the survey.

\section{PROFILE OF PARTICIPANTS}

Among the participants to the survey, 13 come from three main sectors: compulsory education (4), baccalaureate schools (5), and teacher training universities (4). Among the remaining three, one comes from a university and two from other sectors. Most teachers teach in several domains. The distribution of domain of potential application as function of the school type is given in figure 1 .

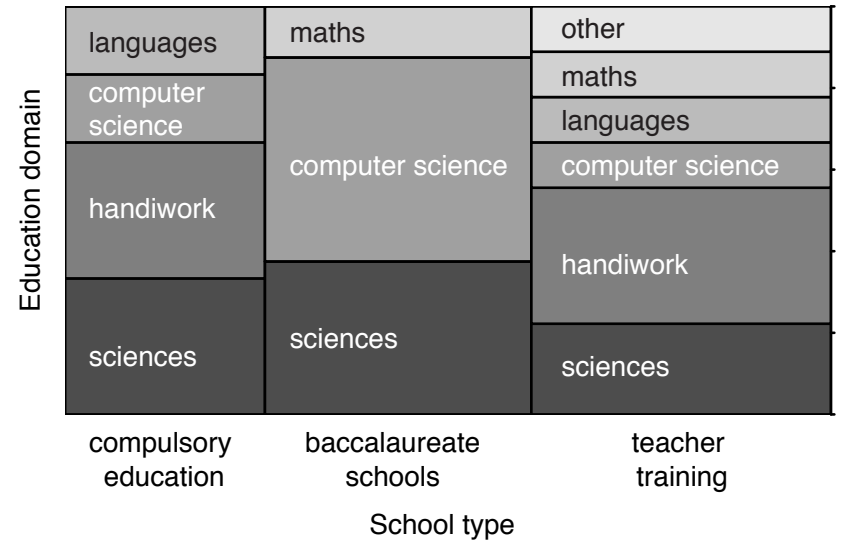

Fig. 1. Distribution of discipline among the three main types of schools where the teachers are active.

The teachers that have been attracted by this activity are well balanced between compulsory education, baccalaureate schools, and teacher training universities but the domain where they would apply the learned technology are very different. Teachers active in teacher training universities cover a broader spectrum, mainly because some of their activities (pedagogy, for instance) are transversal. Teachers active in baccalaureate schools would mainly like to apply technology in education of math, basic sciences and computer science. The correlation between teaching in baccalaureate schools and aiming at applying the technologies learned in computer science is particularly high ( $\mathrm{p}$-value $=0.01572$ by Spearman's correlation test). Teachers in compulsory schools focus much less on computer science and cover more domains, such as handiwork and languages. This difference has many reasons; on one side, handiwork is not present in
TABLE I

THE SURVEY FORM

Profile

- Firstname

- Lastname

- email

- Sector where you are active (compulsory education, baccalaureate schools, vocational education, teacher training and applied sciences universities, university, industry, associations or foundations, others)

- Channel of information about this initiative (personal email or direct contact, colleagues, mailinglist, school, information meeting, media, web, other)

- Attended workshops (give the list)

- Discipline where you would like to apply what you learned (Computer science, maths, sciences, languages, handiwork, history or geography, other)

Evaluation.

Indicate the quality of the following aspects:

- E1: Web site for the teachers (bad, insufficient, sufficient, good, excellent)

- E2: Training for the workshop (bad, insufficient, sufficient, good, excellent)

- E3: Organization of the event (bad, insufficient, sufficient, good, excellent)

- E4: Written educational material (bad, insufficient, sufficient, good, excellent)

- E5: Global appreciation (bad, insufficient, sufficient, good, excellent) Impact of the event.

Position yourself in respect to the following sentences:

- P1: I am always looking for new technologies for my teaching activity I promotion of sciences (no, rather no, rather yes, yes)

- P2: I already use the type of educational tools seen at the festival (no, rather no, rather yes, yes)

- P3: The participation to the workshops is an excellent training opportunity (no, rather no, rather yes, yes)

- P4: I appreciated to be able to check the use of the presented tools (no, rather no, rather yes, yes)

- P5: It is important to receive the material (robot, kit) at the end of the workshop (no, rather no, rather yes, yes)

- P6: It is important to be able to use the material in my class (No, rather no, rather yes, yes)

- P7: I was able to visit the others activities of the festival, such as shows and exhibitions (No, rather no, rather yes, yes)

- P8: I will for sure use what I learned in my activity (No, rather no, rather yes, yes)

- P9: I am motivated to develop new educational documents/activities to use these technologies in my classes (No, rather no, rather yes, yes)

Future of the event.

- If we repeat this action, are you interested in participating? (yes, no)

- Would you encourage your colleagues to participate to the workshop as you did? (yes, no)

baccalaureate schools, on the other side, language seems not a potential target for baccalaureate schools probably because the complexity of language teaching at this school level.

Another clear difference between the teachers of these three main types of schools is their gender, as illustrated in figure 2.

In our case, teachers active in teacher training universities were mostly women. In compulsory education the gender of teachers is well balanced, while in baccalaureate schools we attracted only men.

Finally the communication channels that were used to reach the teachers are also slightly different, as illustrated in figure 3.

Because this training effort was strongly supported by 


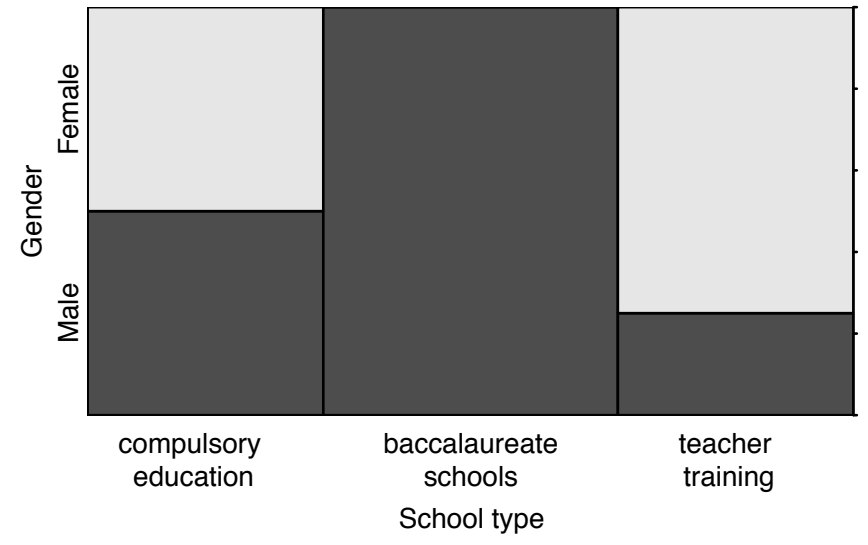

Fig. 2. Distribution of gender of the teachers among the three main schools types.

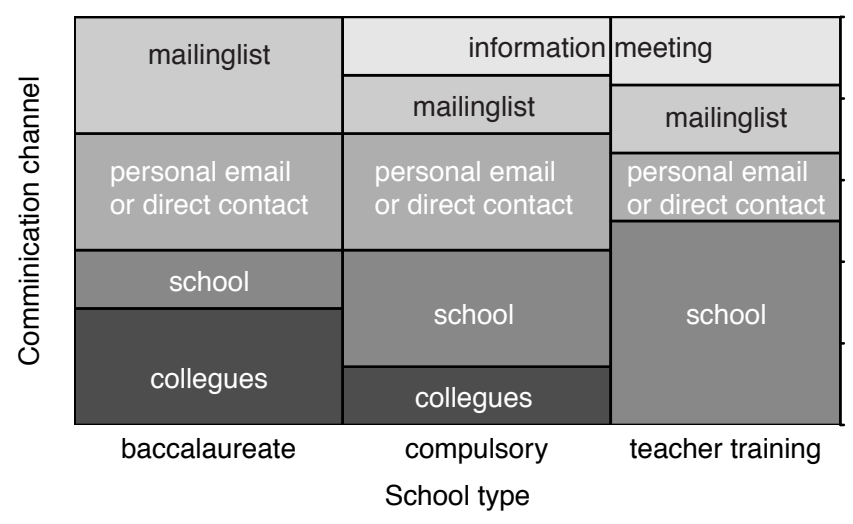

Fig. 3. Communication channels used to reach the teachers as function of the type of school.

the local teacher training university, the teachers of this type of school were mostly informed through the school and local meetings. The teachers from baccalaureate schools seem to be a more coherent group and got more information through colleagues and targeted mailinglists. Compulsory school teachers seems to be a more heterogeneous group, using various communication channels.

\section{FEEDBACK FROM THE TEACHERS}

The feedback to the evaluation questions E1 to E5 are summarized in figure 4 . The worst feedback in the evaluation is given to the organization of the event. Indeed the high participation generated several problems during the festival, making it difficult to circulate and belating workshop participants. This general stress was also felt by teachers in the workshops, who did not find the rooms easily or received little instructions on arrival. The training for the teachers (training session and written material made available) got a mixed evaluation; nearly half-half between positive and negative feedbacks. The written material distributed to the teachers has a slightly lower score. Based on the discussions we had with the teachers, both results seems due to the high expectation in training the teachers have. Most material and training being given by non-teachers, this generated some disappointment.

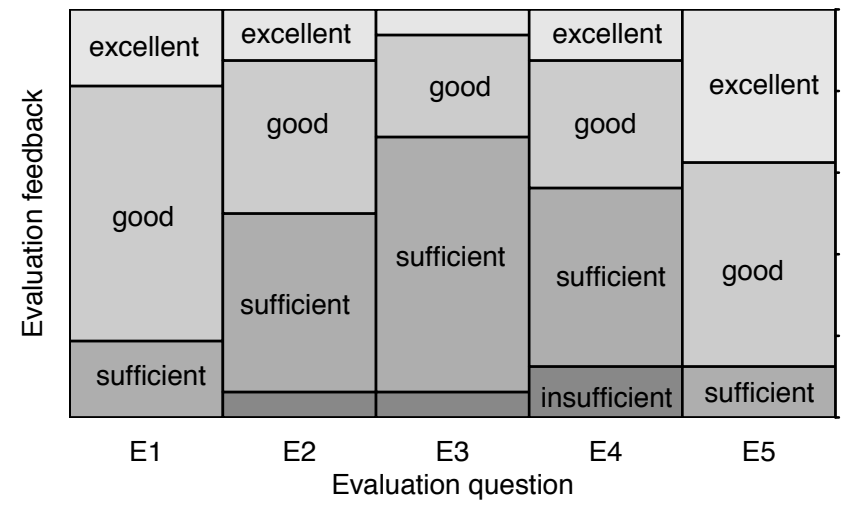

Fig. 4. Summary of the answers to the evaluation questions E1 to E5.

The quality of the WEB portal for the teachers got an excellent evaluation. The best evaluation, finally, is the global one, showing that this action is extremely appreciated by the teachers, despite some minor problems.

It is interesting to analyze more in detail these evaluations in respect to the profile of the participants. None of the evaluations correlates with the type of school. Within the target teaching domains, the only clear correlation is between the web site evaluation (answer to question E1) and the fact to be science teachers (spearman test, $\mathrm{p}$-value $=0.01086$ ) . Only teachers targeting science, but nearly half of them, gave an "excellent" mark to our web site. A lower but still interesting correlation (spearman test, $p$-value $=0.1038$ ) exists between the same teachers and the global evaluation (answer to question E5, illustrated in figure 5). These two results show that our activity was particularly appreciated by teachers targeting sciences as teaching domain. Nevertheless one should note that most of these teachers ( 6 over 7 ) were targeting more than one field and therefore the science target is their best common trait, not excluding other fields.

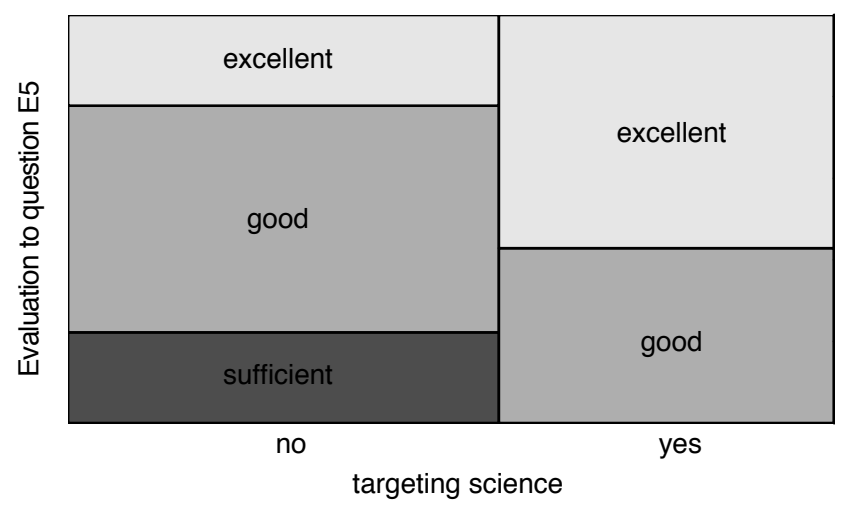

Fig. 5. Global evaluation (answer to question E5) as function of the target domain of application, being science or not.

\section{EVALUATION OF IMPACT}

The feedback to the impact questions P1 to P9 are summarized in figure 6. Most teachers confirm being "always 
looking for new technologies" (question P1), which motivates their participation to this action. Nevertheless 3 of the 16 teachers answered negatively, showing that this type of action can reach teachers not actively looking for this type of educational tools. Less than $40 \%$ of the teachers already use the type of technology seen at the festival (question P2). Very few answer a clear yes to this question, showing that there is a strong potential of improvement. 15 over 16 teachers say that the opportunity to participate to the workshop is a good training opportunity (question P3), confirming that our action is extremely appreciated.

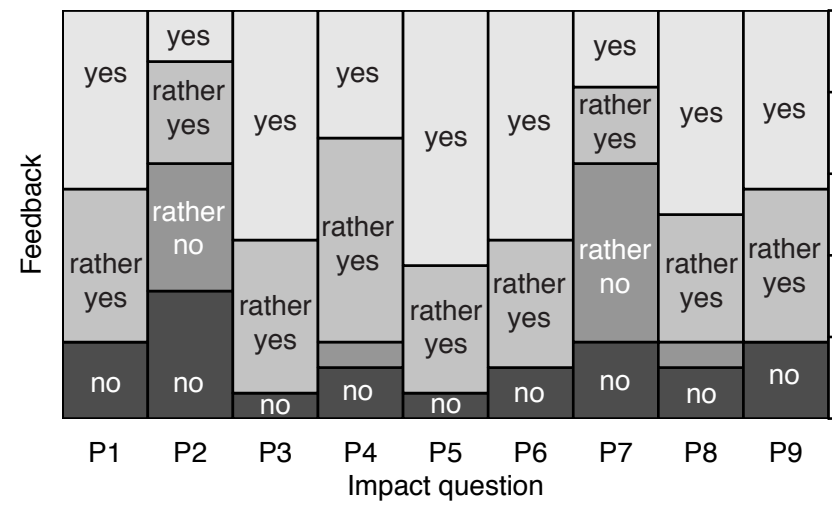

Fig. 6. Summary of the answers to the impact questions P1 to P9.

The possibility to check the use of the tools in a workshop (question P4) is slightly less appreciated, probably because standard classes and workshops present very different working conditions; In workshops every teacher takes care of 2-3 participants, while in a class this number goes up to 18-25. This makes a huge difference and the experience made in a workshop cannot be simply repeated in a class (feedback based on informal discussions). The fact to get the hardware for free is highly appreciated (15 over 16 positive answers to question P5). It is unclear if this is due to personal or professional interest, but the possibility to get the robot used during the workshop has shown to be a very good incentive to the participation. The fact to be able to use the material in class (question P6) is also considered very important by 14/16 teachers. The teachers have been mostly absorbed by the workshop and were not able to attend other activities, as illustrated by the answers to question P7. Finally 13/16 teachers both said being sure to use in their activity what they learned at the festival (P8) and being motivated to develop new educational documents in order to use the equipment in their classes (P9). While the optimism of P8 is encouraging, the motivation shown in P9 was surprising to us. Only 3-4 of these teachers have then started really writing educational material, but this result seems already encouraging.

When looking a little bit closer to the responses, we notice that correlations appear between one school (baccalaureate) and the positive answer to questions P1 (spearman test, pvalue $=0.04623)$, P6 (spearman test, $\mathrm{p}$-value $=0.01981)$, P8 (spearman test, p-value $=0.09692$ ) and P9 (spearman test, $\mathrm{p}$-value $=0.04623$ ). Because of the correlation between this school and the target field of computer science, these correlations appear also between computer-science and the positive answers of the same questions. This shows that baccalaureate school teachers, mostly targeting computerscience, are looking more than others for new technologies for their teaching activities. This clear correlation is shown in figure 7.

I am always looking for new technologies for my teaching activity

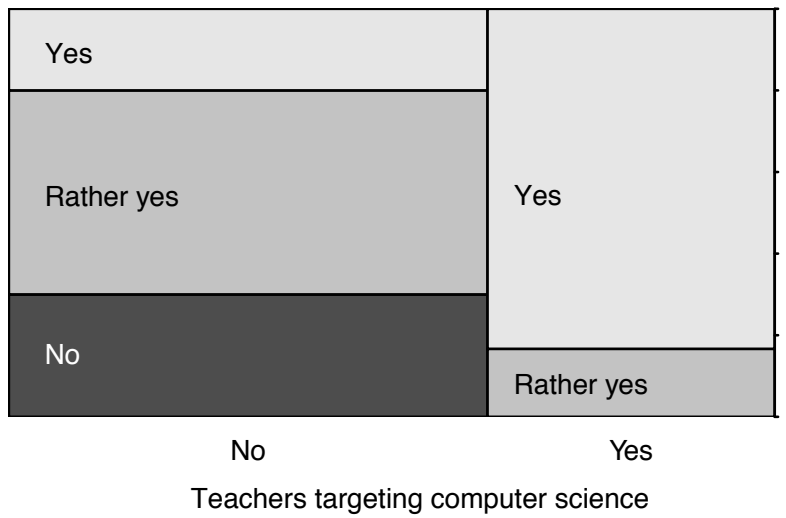

Fig. 7. Answers to question P1 as function of the target use, being computer-science teaching or not (spearman test, $\mathrm{p}$-value $=0.01057$ ).

This group of teachers also specially expects to be able to use the material in their classes. Finally they are particularly motivated in using these technologies even by investing efforts in preparing new educational documents for it. This clear motivation to spend efforts in developing educational material by teachers in computer sciences is illustrated graphically in figure 8 .

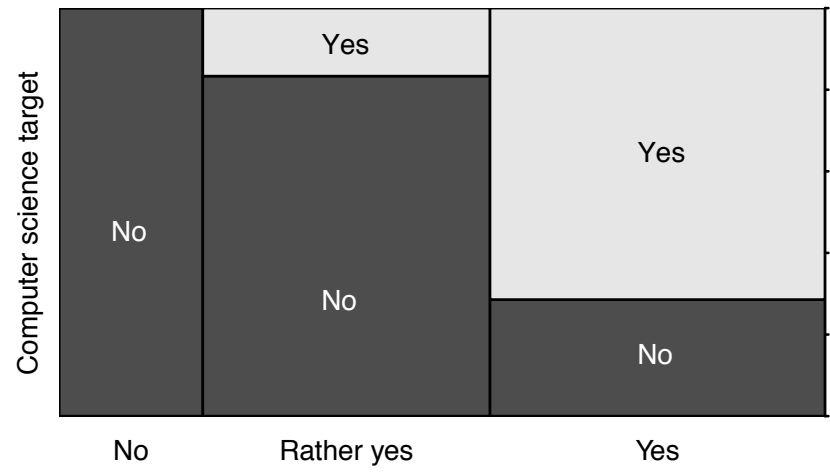

I am motivated to develop new educational documents/activities to use these technologies in my classes

Fig. 8. Portion of teachers targeting computer sciences education as fonction of the level of motivation shown answering question P9.

It has to be noted that with a higher p-value (0.1142) the teachers of baccalaureate schools are also those mostly using already the tools presented at the festival. This trend is illustrated graphically in figure 9. 
I already use the type of educational tools seen at the festival

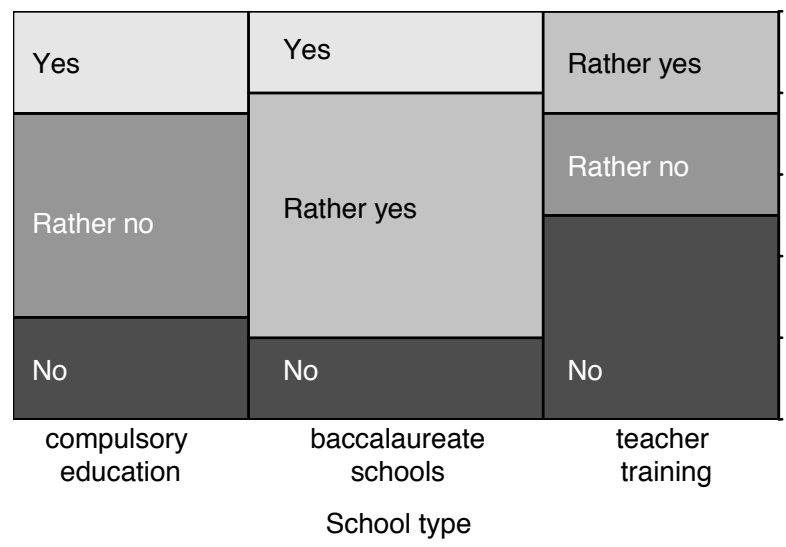

Fig. 9. Answer to question P2 as function of the school type.

\section{FUTURE OF THIS ACTIVITY}

All teachers answered positively to the last two questions, asking if they would come again and if they would suggest the participation to colleagues. This is probably the best confirmation of the appreciation of the event.

\section{DISCUSSION AND CONCLUSION}

Many institutions organize open doors or science festivals to get in touch with the local population. This type of event is targeting the large public but basically reaches only people who are already interested in the topic addressed by the event. To really reach the large public one possible way is to use schools through the action of their teachers. The problem here is how to motivate the teachers. This paper presents a way to motivate teachers by inviting them to attend events such as the EPFL robotic festival. The goal of this action is to use the resources available during such events to train the teachers in a concrete application case. A survey made after the 2011 edition of the festival helped in understanding how successful this action was and which factors made it successful.

Teacher are ready to come and get trained only if they see a direct positive impact of this activity within their teaching activity. This means that they should be able to directly use in their classes what they learned during the event. To reach this goal, we provided educational material, training, and the possibility to get the equipment used during the workshops for free. While the training activity and the educational material were not meeting the expectations of the teachers, the fact to be able to get the equipment for free is extremely appreciated and the global feedback is excellent. The most interested and active teachers are those working in baccalaureate schools and targeting the use of robotic technology in computer-science teaching. This is probably somehow related to the introduction in the french speaking part of Switzerland of new computer-science courses at the baccalaureate school level.
As a conclusion, using existing events of promotion of science and technology to better involve local teachers is an extremely interesting opportunity that can have a high degree of success if one meets the expectations of the teachers in term of impact on their activity. The experience made at EPFL got excellent feedback and is extending furthermore for the 2012 edition of the robotics festival. A more specific effort will be made in improving the training before the workshops and the educational documents distributed among the teachers.

\section{ACKNOWLEDGMENTS}

This research was supported by the Swiss National Science Foundation through the National Centre of Competence in Research Robotics. The teacher training at the EPFL robotic festival is an action supported by the Swiss Academy of Engineering Sciences (SATW).

\section{REFERENCES}

[1] CERI, "New millennium learners," in OECD/CERI International Conference "Learning in the 21st Century: Research, Innovation and Policy". OECD, 2008.

[2] M. Demichele, G. Demo, and S. Siega, "A piedmont schoolnet for a k12 mini-robots programming project: Experiences in primary schools," in Workshop Proceedings of Intl. Conf. on Simulation, Modeling and Programming for Autonomous Robots (SIMPAR 2010). Citeseer, 2008.

[3] A. Bredenfeld and T. Leimbach, "The roberta initiative," in Workshop Proceedings of Intl. Conf. on Simulation, Modeling and Programming for Autonomous Robots (SIMPAR 2010), 2010, pp. 558-567.

[4] N. Rusk, M. Resnick, R. Berg, and M. Pezalla-Granlund, "New pathways into robotics: Strategies for broadening participation," Journal of Science Education and Technology, vol. 17, no. 1, pp. 59-69, 2008.

[5] F. Riedo, J. Fink, M. Freire, and F. Mondada, "Analysis of impact of an annual robotics festival," in Proceedings of the IEEE International Workshop on Advanced Robotics and its Social Impacts. IEEE, 2012.

[6] (2011). [Online]. Available: http://www.beebot.org.uk

[7] (2011). [Online]. Available: http://mindstorms.lego.com

[8] (2011). [Online]. Available: http://www.parallax.com/go/boebot 